\title{
Measurement of atmospheric sesquiterpenes by proton transfer reaction-mass spectrometry (PTR-MS)
}

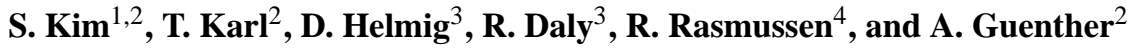 \\ ${ }^{1}$ Advanced Study Program, National Center for Atmospheric Research, Boulder, CO, USA \\ ${ }^{2}$ Atmospheric Chemistry Division, National Center for Atmospheric Research, Boulder, CO, USA \\ ${ }^{3}$ Institute of Arctic and Alpine Research, University of Colorado, Boulder CO, USA \\ ${ }^{4}$ Oregon Graduate Institute, Beaverton, OR, USA
}

Received: 23 October 2008 - Published in Atmos. Meas. Tech. Discuss.: 4 December 2008

Revised: 2 March 2009 - Accepted: 29 March 2009 - Published: 9 April 2009

\begin{abstract}
The ability to measure sesquiterpenes (SQT; $\mathrm{C}_{15} \mathrm{H}_{24}$ ) by a Proton-Transfer-Reaction Mass Spectrometer (PTR-MS) was investigated. SQT calibration standards were prepared by a capillary diffusion method and the PTR-MSestimated mixing ratios were derived from the counts of product ions and proton transfer reaction constants. These values were compared with mixing ratios determined by a calibrated Gas Chromatograph (GC) coupled to a Flame Ionization Detector (GC-FID). Product ion distributions from soft-ionization occurring in a selected ion drift tube via proton transfer were measured as a function of collision energies. Results after the consideration of the mass discrimination of the PTR-MS system suggest that quantitative SQT measurements within 20\% accuracy can be achieved with PTR-MS if two major product ions $\left(\mathrm{m} / z .149^{+}\right.$and $\left.205^{+}\right)$, out of seven major product ions $\left(\mathrm{m} / z 81^{+}, 95^{+}, 109^{+}\right.$, $123^{+}, 135^{+}, 149^{+}$and $205^{+}$), are accounted for. Considerable fragmentation of bicyclic sesquiterpenes, i.e. $\beta$ caryophyllene and $\alpha$-humulene, cause the accuracy to be reduced to $50 \%$ if only the parent ion $\left(\mathrm{m} / z 205^{+}\right)$is considered. These findings were applied to a field dataset collected above a deciduous forest at the PROPHET (Program for Research on Oxidants: Photochemistry, Emissions, and Transport) research station in 2005. Inferred average daytime ecosystem scale mixing ratios (fluxes) of isoprene, sum of monoterpenes (MT), and sum of SQT exhibited values of $15 \mu \mathrm{g} \mathrm{m}^{-3}\left(4.5 \mathrm{mg} \mathrm{m}^{-2} \mathrm{~h}^{-1}\right), 1.2 \mu \mathrm{g} \mathrm{m}^{-3}$ $\left(0.21 \mathrm{mg} \mathrm{m}^{-2} \mathrm{~h}^{-1}\right)$, and $0.0016 \mu \mathrm{g} \mathrm{m}^{-3}\left(0.10 \mathrm{mg} \mathrm{m}^{-2} \mathrm{~h}^{-1}\right)$, respectively. A range of MT and SQT reactivities with respect to the $\mathrm{OH}$ radical was calculated and compared to an
\end{abstract}

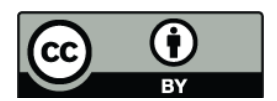

Correspondence to: S. Kim (saewung@ucar.edu) earlier study inferring significantly underestimated $\mathrm{OH}$ reactivities due to unknown terpenes above this deciduous forest. The results indicate that incorporating these MT and SQT results can resolve $\sim 30 \%$ of missing $\mathrm{OH}$ reactivity reported for this site.

\section{Introduction}

Sesquiterpenes (SQT; $\mathrm{C}_{15} \mathrm{H}_{24}$ ) represent a class of terpenoid compounds (e.g. isoprene; $\mathrm{C}_{5} \mathrm{H}_{8}$, monoterpenes (MT); $\mathrm{C}_{10} \mathrm{H}_{16}$, and sesquiteprenes) that have received increasing attention in plant biology and atmospheric chemistry due to their biologically active role and their potential for forming secondary organic aerosol (SOA). Similarly to MT, SQT are derived from the biosynthesis of plants (Kesselmeier and Staudt, 1999; Farmer, 2001; Schnee et al., 2006; Gershenzon, 2007). These compounds are thought to be essential bio-signaling molecules, such as salicylates and jasmonates, which participate in plant-to-plant communication. Emissions and photochemistry of isoprene and MT have been intensively studied due to their significance for tropospheric ozone chemistry and their impact on SOA formation. A limited number of studies have illustrated that emissions of SQT are significantly lower than those of isoprene and MT (Duhl et al., 2008), nonetheless the physicochemical properties of SQT (e.g. low vapor pressure and high reactivity) suggest that they may play an important role influencing atmospheric chemistry and aerosol formation processes (Griffin et al., 1999; Lee et al., 2006; Liao et al., 2007).

Indirect evidence from several field campaigns in forest canopies has indicated that not all biogenic volatile organic compounds (BVOC) (such as SQT) are being accounted for.

Published by Copernicus Publications on behalf of the European Geosciences Union. 
Table 1. Summary for the drift tube voltage and pressure used to adjust listed E/Ns for this study.

\begin{tabular}{ccc}
\hline E/N (Townsend) & Pressure (Torr) & Voltage (V) \\
\hline 76 & 2.3 & 400 \\
87 & 2.3 & 450 \\
97 & 2.3 & 500 \\
105 & 2.3 & 540 \\
117 & 2.3 & 600 \\
117 & 1.9 & 500 \\
127 & 1.9 & 540 \\
141 & 1.9 & 600 \\
\hline
\end{tabular}

$\mathrm{OH}$ reactivity measurements during the Program for Research on Oxidants: Photochemistry, Emissions and Transport (PROPHET) in 2000 suggested that the significant excess $\mathrm{OH}$ reactivity, unexplained by measured VOC, was positively correlated with ambient temperature. Since the temperature dependence of the excess $\mathrm{OH}$ reactivity was very similar to that of isoprene and MT emissions, the authors suggested that most of the unmeasured species causing the excess $\mathrm{OH}$ reactivity were probably terpene-like compounds (Di Carlo et al., 2004). Karl et al. (2007) reported that part of a systematic discrepancy between calculated $[\mathrm{OH}]$ from the mixed-box technique and box-model calculated $[\mathrm{OH}]$ at a tropical forest site could be resolved if ambient levels of reactive SQT reached at least $1 \%$ of isoprene mixing ratios. Unexpected chemical loss of $\mathrm{O}_{3}$ in the Sierra Nevada forest was also interpreted as an indication of unmeasured BVOC (Kurpius and Goldstein, 2003). In addition, Holzinger et al. (2005) hypothesized the existence of large amounts of unknown very reactive BVOC above a Ponderosa pine forest in Central California.

Unmeasured BVOC could also have implications for new particle formation via atmospheric oxidation. Bonn et al. (2007) suggested that the stabilized Criegee biradicals from the reaction between ozone and SQT could be an important source for the formation of stable atmospheric clusters that were observed in a boreal forest (Hyytiälä, Finland). In a later study, Boy et al. (2008) also highlighted the role of SQT in new particle formation within a high alpine forest ecosystem in Colorado Rocky Mountains. In addition, chamber studies used to assess secondary organic aerosol (SOA) formation potential found high yields from the ozonolysis of $\beta$-caryophyllene (39\% to $100 \%$; Hoffmann et al. (1997), Jaoui et al. (2003), and Lee et al. (2006)).

Measurements of SQT are extremely difficult due to their reactive nature and low volatility. Recently, a series of research activities has characterized sampling procedures to generate calibration standards, minimize sampling losses, and define quantitative analysis methods by conventional gas chromatographic techniques (GC) (Helmig et al., 2003; Pollmann et al., 2005). To date SQT emission studies have mostly focused on plant enclosure measurements, where ozone is scrubbed in order to avoid sample losses (Duhl et al., 2008). Very few studies have succeeded in identifying and quantifying SQT in ambient air (Helmig and Arey, 1993; Hoffmann, 1995). Proton-transfer-reaction mass spectromentry (PTR-MS) has recently been proven to be a valuable tool for BVOC flux research for its high sensitivity and fast time resolution $(\sim \mathrm{Hz}$, de Gouw and Warneke, 2007; Karl et al., 2001). However due to the lack of proven calibration procedures and quantitative knowledge on fragmentation patterns, only a limited number of studies have reported results on SQT using PTR-MS (Lee et al., 2006; Boy et al., 2008). Moreover, the lower sensitivity of PTR-MS for large molecules such as SQT (MW 204 $\mathrm{g} \mathrm{mol}^{-1}$ ), caused by the low transmission efficiency of the quadrupole mass filter (Steinbacher et al., 2004), must be considered. In addition, fragmentation patterns need to be known to deduce typical sensitivities for compounds in the higher molecular weight range (e.g. 150-230 amu).

This study provides an assessment of current capabilities for measuring SQT by PTR-MS including the mass discrimination of the PTR-MS system. We explore fragmentation patterns and analytical characteristics of a series of SQT as a function of two parameters: collisional energy, defined as the ratio between the electrical field strength across the drift tube (E) and the number density $(\mathrm{N})$, and relative humidity, which affects sensitivities via cluster formation (de Gouw and Warneke, 2007) and fragmentation (Tani et al., 2004). The number density of water can affect the kinetic energy of ions in the drift tube influencing water cluster distributions and the "softness" of proton transfer reactions toward fragmentation processes in the drift tube (Tani et al., 2004; Tani et al., 2003). Various E/N values, adjusted by voltages and pressures in the drift tube for this study, are summarized in Table 1. We also present an intercomparison of PTR-MS results with complementary techniques (GC-FID) for evaluation purposes and apply our findings to deduce quantitative emissions and mixing ratios of total SQT in ambient air from a dataset collected at the PROPHET Field site.

\section{Methods}

\subsection{PTR-MS}

Basic technical descriptions for PTR-MS can be found in Lindinger et al. (1998), Hansel et al. (1999), and de Gouw and Warneke (2007). A commercial highsensitivity PTR-MS (IONICON, Austria, with a QMZ 422 quadrupole, Balzers, Switzerland) instrument was used for this study. The instrument configuration has been 


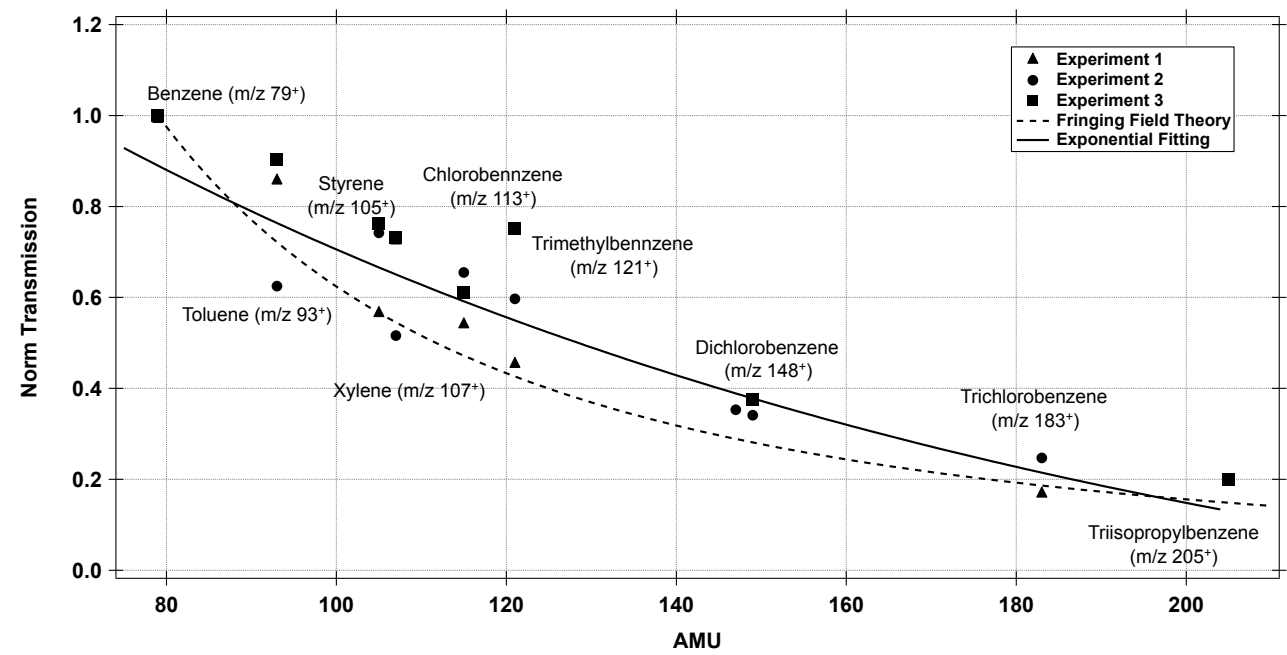

Fig. 1. Mass transmission from three experiments as indicated by different shapes of data points. Two transmission curves, based on the fringing field theory (dashed line), and a fitting curve by an exponential function (solid line) are also indicated.

modified for several ground and airborne deployments (e.g. Karl et al., 2004, 2005). Instrumental sensitivities for methanol, acetonitrile, acetaldehyde, acetone, isoprene, methyl vinyl ketone, benzene, toluene, camphene, $o, p, m$ xylenes, 1,2,4 and 1,3,5-trimethylbenzenes, chlorobenzene, $o, p, m$-dichlorobenzene, and 1,2,4-trichlorobenzene were determined by multiple-point calibrations (range of few ppbv to few tens ppbv) by mixing VOC-scrubbed air with two gravimetrically-prepared VOC standards (Matheson TriGas, USA, $1 \mathrm{ppmv} \pm 5 \%$; NCAR, USA, $1 \mathrm{ppmv} \pm 5 \%$ ). The lower limit of detection for these compounds is usually less than $30 \mathrm{pptv}$ ( $2 \sigma$ with a five seconds integration time). For our instrument basic operational paramters and sensitivity remained similar to the commercial instruments. Typical sensitivities normalized to $10^{6}$ counts per seconds (cps) $\mathrm{H}_{3} \mathrm{O}^{+}$(normalized cps (ncps) ppbv ${ }^{-1}$ ) at $2.3 \mathrm{mbar}$ drift pressure and $115 \mathrm{Td}$ were $14 \mathrm{ncps} \mathrm{ppbv}^{-1}, 20 \mathrm{ncps} \mathrm{ppbv}^{-1}$, and $26 \mathrm{ncpspbv}^{-1}$ for benzene, toluene, and acetone, respectively. The measured sensitivities are comparable to the theoretical sensitivities (e.g., $14 \mathrm{ncpsppbv}^{-1}$ for a reaction rate constant $(\mathrm{k})$ of $2.2 \times 10^{-9}$ molecule ${ }^{-1} \mathrm{~cm}^{3} \mathrm{~s}^{-1}$, and $22 \mathrm{ncps} \mathrm{ppbv}^{-1}$ for $\mathrm{k}=3.4 \times 10^{-9}$ molecule $\mathrm{cm}^{-1} \mathrm{~cm}^{3}$ ) based on proton transfer rates for these compounds $\left(1.8 \times 10^{-9}\right.$ molecule $^{-1} \mathrm{~cm}^{3} \mathrm{~s}^{-1}, 2.3 \times 10^{-9}$ molecule $^{-1} \mathrm{~cm}^{3}$ $\mathrm{s}^{-1}$, and $4.1 \times 10^{-9}$ molecule $^{-1} \mathrm{~cm}^{3} \mathrm{~s}^{-1}$ for benzene, toluene, and acetone, respectively; Spanel and Smith, 1995). For the typical range of $\mathrm{H}_{3} \mathrm{O}^{+}$ion counts $\left(1\right.$ to $1.5 \times 10^{7} \mathrm{cps}$ ), these response factors relate to total sensitivities between $140-400 \mathrm{cps} \mathrm{ppbv}^{-1}$.

\subsection{Mass discrimination of the Quadrupole Mass Filter}

The mass discrimination of PTR-MS is discussed by Steinbacher et al. (2004). They found that the sensitivity starts decreasing at $\mathrm{m} / \mathrm{z} 80$. This mass discrimination is partly caused by the fringing field effect of the quadrupole mass filter (QMS) (Dawson 1972, 1974, 1975). Dawson (1975) presented numerical and graphical explanations of the fringing field effect, caused by the electrical field in between an ion lens and the entrance of the QMS. This study illustrated that heavier ions spend more time around and in the fringing field. This causes instability of trajectories in the QMS. The transmission efficiency would then be expected to decrease with the square of the resolving power. It is therefore important to carefully consider QMS mass discrimination in order to quantify the relative distribution of high molecular weight compounds (e.g. SQT). Here, an experimental transmission curve of the QMS was obtained by injecting an aromatic gas standard (Matheson TriGas, USA) covering a mass range between $\mathrm{m} / \mathrm{z} 79^{+}-181^{+}$at $117 \mathrm{Td}$. In addition, the instrument sensitivity for a 1,3,5-triisopropylbenzene (TIPB) standard, generated by the capillary diffusion system described in the following section, was used to specifically assess the transmission efficiency at $\mathrm{m} / z 205^{+}$. These aromatic compounds have been used for mass discrimination assessments since no fragmentation is detected in the drift tube of PTR-MS (Taipale et al., 2008). The results obtained from three different experiments shown in Fig. 1 clearly indicate the mass discrimination effect for the mass range of $79^{+}$to $210^{+}$amu. An empirical transmission curve was fitted using an exponential function. In addition, the curve based on fringing field theory illustrates how the transmission efficiency decreases with the square of the resolving power. Although the transmission curve based on the fringing field theory follows the general trend of measured data points, we apply the exponential regression line for further analysis. The difference between measured and theoretical transmission from the fringing field theory is likely caused by additional factors, which can effect the mass discrimination (e.g. ion reflection, 
Table 2. List of SQT for this study and their identified products from proton transfer reactions. Abundances of product ions are summarized for $117 \mathrm{Td}, 76 \mathrm{Td}, 141 \mathrm{Td}$. For $117 \mathrm{Td}$, transmission-corrected abundances are also presented*. For purpose of comparison, available SIFTMS results (Dhooghe et al., 2008)** are also listed.

\begin{tabular}{|c|c|c|c|c|c|c|}
\hline \multirow{2}{*}{ Species } & \multirow{2}{*}{ Fragment Ions } & \multicolumn{3}{|c|}{ Abundance (\%) at $117 \mathrm{Td}$} & \multicolumn{2}{|c|}{ E/N Dependency } \\
\hline & & PTR-MS & $\begin{array}{c}{ }^{*} \text { PTR_MS } \\
\text { T.C. }\end{array}$ & ${ }^{* *}$ SIFT-MS & EN 76 & EN 141 \\
\hline \multirow[t]{8}{*}{$\beta$-Caryophyllene } & MS $81\left(\mathrm{C}_{6} \mathrm{H}_{9}^{+}\right)$ & 16 & 6.7 & 4 & 8.9 & 19 \\
\hline & $\operatorname{MS} 95\left(\mathrm{C}_{7} \mathrm{H}_{11}^{+}\right)$ & 18 & 8.2 & 9 & 16.2 & 18 \\
\hline & MS $109\left(\mathrm{C}_{8} \mathrm{H}_{13}^{+}\right)$ & 15 & 8.6 & 10 & 15.7 & 16 \\
\hline & $\operatorname{MS} 123\left(\mathrm{C}_{9} \mathrm{H}_{15}{ }^{+}\right)$ & 6.9 & 5.3 & 7 & 9.3 & 7.2 \\
\hline & $\operatorname{MS} 135\left(\mathrm{C}_{10} \mathrm{H}_{15}{ }^{+}\right)$ & 8.1 & 7.1 & 8 & 9.3 & 8.6 \\
\hline & $\operatorname{MS} 137\left(\mathrm{C}_{10} \mathrm{H}_{17}{ }^{+}\right)$ & 7.3 & 6.6 & 7 & 8.6 & 7.1 \\
\hline & MS $149\left(\mathrm{C}_{11} \mathrm{H}_{17}^{+}\right)$ & 11 & 14 & 16 & 13 & 13 \\
\hline & MS $205\left(\mathrm{C}_{15} \mathrm{H}_{25}{ }^{+}\right)$ & 10 & 44 & 30 & 19 & 11 \\
\hline \multirow[t]{8}{*}{$\alpha$-Humulene } & MS 81 & 9.7 & 3.5 & 2 & 0.0 & 4.2 \\
\hline & MS 95 & 17 & 7.2 & 7 & 17 & 24 \\
\hline & MS 109 & 15 & 7.6 & 7 & 14 & 19 \\
\hline & MS 123 & 12 & 6.8 & 7 & 12 & 13 \\
\hline & MS 135 & 6.5 & 4.4 & 4 & 7 & 6.6 \\
\hline & MS 137 & 4 & 2.8 & 2 & 5 & 3.7 \\
\hline & MS 149 & 10 & 8.3 & 9 & 10 & 12 \\
\hline & MS 205 & 25 & 60 & 54 & 36 & 17 \\
\hline \multirow[t]{8}{*}{ Aromadendrene } & MS 81 & 5.1 & 1.6 & \multirow{8}{*}{ N/A } & 4.0 & 8.5 \\
\hline & MS 95 & 12 & 4.7 & & 7.1 & 12 \\
\hline & MS 109 & 9.4 & 4.1 & & 8.0 & 11 \\
\hline & MS 123 & 5.2 & 2.7 & & 4.0 & 4.7 \\
\hline & MS 135 & 7.2 & 4.4 & & 5.6 & 6.2 \\
\hline & MS 137 & 1.1 & 1.0 & & 1.8 & 1.0 \\
\hline & MS 149 & 13 & 10 & & 10 & 18 \\
\hline & MS 205 & 34 & 72 & & 44 & 22 \\
\hline \multirow[t]{7}{*}{$\alpha$-Cubebene } & MS 81 & 6.6 & 1.8 & \multirow{7}{*}{ N/A } & 4.0 & 10 \\
\hline & MS 95 & 11 & 3.4 & & 8.5 & 13 \\
\hline & MS 109 & 11 & 4.0 & & 8.7 & 13 \\
\hline & MS 123 & 5.5 & 2.4 & & 4.2 & 7.2 \\
\hline & MS 135 & 0 & 0.0 & & 0.0 & 0.0 \\
\hline & MS 137 & 7.4 & 3.9 & & 6.2 & 7.6 \\
\hline & MS 149 & 19 & 12 & & 12 & 26 \\
\hline
\end{tabular}

retarded ion entry, ion exit effects, and mass discriminations from the detector; Dawson, 1975). We applied the empirical transmission curve to estimate the actual abundances of product ions (mother and fragmented ions) over the product ion mass range of $m / z 81^{+}$to $m / z 205^{+}$.

\subsection{Capillary diffusion calibration system and GC-FID}

Gas-phase standards of eight SQT, as summarized in Table 2, were generated from the capillary diffusion system (CDS). The system allows for the use of outflow from either a single 
Table 2. Continued.

\begin{tabular}{|c|c|c|c|c|c|c|}
\hline \multirow[t]{8}{*}{ Neoclovene } & MS 81 & 5.0 & 1.8 & 0 & 2.5 & 8.2 \\
\hline & MS 95 & 16 & 6.6 & 3 & 9.2 & 18 \\
\hline & MS 109 & 15 & 7.2 & 3 & 8.1 & 15 \\
\hline & MS 123 & 2.3 & 1.3 & 2 & 1.6 & 2.0 \\
\hline & MS 135 & 9.8 & 6.7 & 2 & 8.3 & 8.6 \\
\hline & MS 137 & 0 & 0 & 0 & 0.0 & 0.0 \\
\hline & MS 149 & 31 & 26 & 8 & 28 & 28 \\
\hline & MS 205 & 21 & 50 & 79 & 38 & 14 \\
\hline \multirow[t]{8}{*}{ Isolongifolene } & MS 81 & 2.2 & 1.0 & 0 & \multirow{8}{*}{ N/A } & 3.7 \\
\hline & MS 95 & 10 & 3.3 & 0 & & 7.3 \\
\hline & MS 109 & 7.1 & 2.6 & 0 & & 6.8 \\
\hline & MS 123 & 2.3 & 1.0 & 0 & & 1.9 \\
\hline & MS 135 & 4.4 & 2.3 & 0 & & 2.7 \\
\hline & MS 137 & 0.8 & 0.4 & 0 & & 1.0 \\
\hline & MS 149 & 36 & 22 & 2 & & 45 \\
\hline & MS 205 & 37 & 67 & 97 & & 15 \\
\hline \multirow[t]{8}{*}{ d-Cadinene } & MS 81 & 4.3 & 1.0 & \multirow{8}{*}{ N/A } & 1.7 & 13 \\
\hline & MS 95 & 3.2 & 1.0 & & 1.2 & 7.9 \\
\hline & MS 109 & 2.9 & 1.0 & & 1.1 & 6.9 \\
\hline & MS 123 & 0 & 0.0 & & 1.0 & 2.3 \\
\hline & MS 135 & 2.2 & 1.0 & & 1.3 & 4.2 \\
\hline & MS 137 & 0 & 0.0 & & 1.0 & 1.0 \\
\hline & MS 149 & 4.4 & 2.0 & & 1.6 & 12 \\
\hline & MS 205 & 82 & 95 & & 92 & 54 \\
\hline \multirow[t]{6}{*}{ triisopropylbenz } & MS 79 & 7.0 & 1.2 & \multirow{6}{*}{ N/A } & 2.5 & 45 \\
\hline & MS 86 & 1.0 & 0.0 & & 1.0 & 1.0 \\
\hline & MS 121 & 3.0 & 1.0 & & 2.0 & 4.0 \\
\hline & MS 163 & 3.2 & 1.6 & & 2.8 & 5.5 \\
\hline & MS 189 & 5.9 & 4.7 & & 3.6 & 8.1 \\
\hline & MS 205 & 80 & 92 & & 88 & 37 \\
\hline
\end{tabular}

channel $\left(\sim 10 \mathrm{ml} \mathrm{min}^{-1}\right)$ or mixtures of a combination of channels. The output from the CDS can be dynamically diluted with VOC-scrubbed ambient air to yield SQT standards ranging from $100 \mathrm{~s}$ of pptv to $10 \mathrm{~s}$ of ppbv levels. Diffusion rates of each channel were previously quantified by gravimetric measurements and were monitored with a calibrated, online GC-FID instrument (HP 5890 with a DB-1 capillary column, Helmig et al., 2004). Test samples with varying humidity were prepared by passing the VOC-scrubbed dilution air though a glass bubbler.

\subsection{Estimation of sampling line losses}

A $40 \mathrm{~m}$ Teflon line (1/4" O.D.) was purged with VOCscrubbed air at $251 \mathrm{~min}^{-1}$. A B-caryophyllene standard was introduced at the inlet end and diluted by the VOC-scrubbed airflow resulting in concentrations of $\sim 20 \mathrm{ppbv}$. The relative concentration difference between inlet and outlet was measured by PTR-MS at constant temperature. Temperatures were varied between $0^{\circ} \mathrm{C}$ and $40^{\circ} \mathrm{C}$ by placing the tubing into a temperature-controlled environmental chamber (Conviron, Model BDW40, CA). 

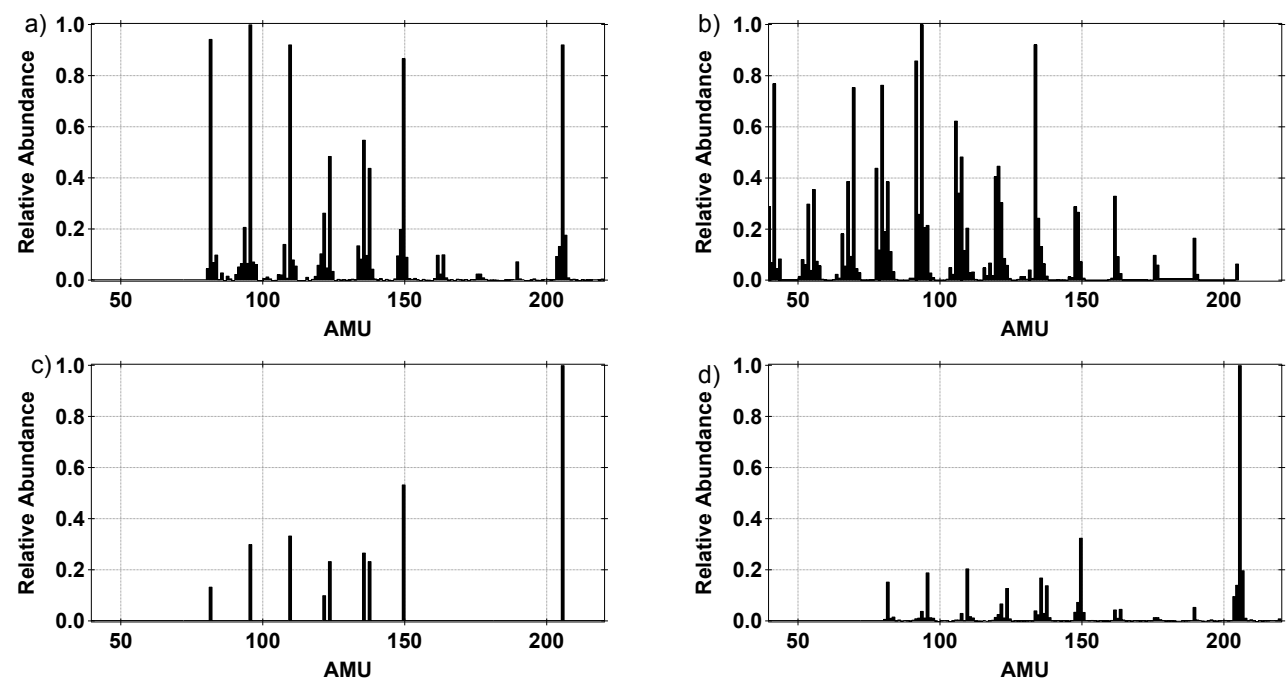

Fig. 2. Mass spectra of $\beta$-caryophyllene obtained from (a) PTR-MS (this study), (b) electron impact (EI; from NIST Standard Reference Database, http://webbook.nist.gov/chemistry), and (c) SIFT-MS (Dhooghe et al., 2008) corrected for mass discrimination. The mass discrimination- corrected PTR-MS spectrum from this study is presented in (d).

\subsection{Emission estimation based on Lagrangian disper- sion model}

A VOC gradient system similar to that described by Karl et al. (2004) was deployed during a field study at the PROPHET Tower (at the University of Michigan Biological Station (UMBS)) for a 3-week period in August 2005 (23 July 200512 August, 2005). The site is situated in the transition zone between mixed hardwood and boreal forests. Bigtooth aspen (Populus grandidentata) and trembling aspen (Populus tremuloides) are the dominant species within the footprint of the tower and are the major source for isoprene emissions (Curtis et al., 2002). Air was pulled through a $40 \mathrm{~m}$ Teflon line (1/4" O.D.) from the top of the sampling tower at a high flow rate $\left(\sim 181 \mathrm{~min}^{-1}\right.$, reducing the pressure inside the line to $400 \mathrm{mbar}$, in order to avoid water condensation, minimize memory effects, and assure a fast response time. The overall air residence time in the sampling line was $\sim 6 \mathrm{~s}$, measured by introducing an isoprene and acetone pulse at the top of the tower. The gradient sampling inlet line was attached to a pulley controlled by an automated winch, and canopy air was sampled continuously between $8 \mathrm{~m}$ and $24 \mathrm{~m}$ heights above ground level by the moving inlet with a constant speed of $0.1 \mathrm{~m} \mathrm{~s}^{-1}$.

Source/sink profiles were computed according to,

$$
\mathrm{C}-\mathrm{C}_{\mathrm{ref}}=\mathrm{D} \cdot \mathrm{S}
$$

where $\mathrm{C}$ is the concentration vector, $\mathrm{C}_{\mathrm{ref}}$ is the concentration at reference height $24 \mathrm{~m}, \mathrm{D}$ is the dispersion matrix and $\mathrm{S}$ is the source/sink vector. Parameterization of the dispersion matrix (21 concentration layers and 5 source/sink layers) was based on measured turbulent profiles and estimated Lagrangian timescales as described by Karl et al. (2004).
For more detailed information on inverse Lagrangian modeling we refer the reader to Raupach (1989). We compared PTR-MS-estimated above-canopy fluxes with eddy covariance measurements (sonic anemometer, Applied Technologies, SATI-K), thoroughly described in Turnipseed et al. (2009).

\section{Results and discussion}

\subsection{Product ion distributions of sesquiterpenes}

\subsubsection{Observed product ions}

Figure 2 shows examples of mass spectra of $\beta$-caryophyllene obtained from three different techniques including (a) PTRMS (at $117 \mathrm{Td}$ ), (b) electron impact (EI; from the NIST Standard Reference Database), and (c) a selective ion flow tube (SIFT)-MS (Dhooghe et al., 2008). As expected, the most energetic method, EI shows much more fragmentation when compared to chemical ionization methods (SIFT and PTR-MS). The PTR-MS spectrum corrected for the mass discrimination by the empirical transmission curve of Fig. 1 is presented in Fig. 2d for comparison purposes. These results indicate that fragmented ions appear on identical masses for both PTR-MS and SIFT-MS. The product ion distribution also qualitatively agrees with those reported by Lee et al. (2006). Normalized abundances of ions produced from dissociative proton transfer are summarized in Table 2. It is noted that we have excluded ions $\left(\mathrm{m} / \mathrm{z} 121^{+}, 135^{+}, 163^{+}\right.$, $175^{+}$, and $189^{+}$), which are products of charge transfer from $\mathrm{O}_{2}^{+}$, as demonstrated by Dhooghe et al. (2008). While $\mathrm{O}_{2}^{+}$ions are typically maintained at low levels in PTR-MS 

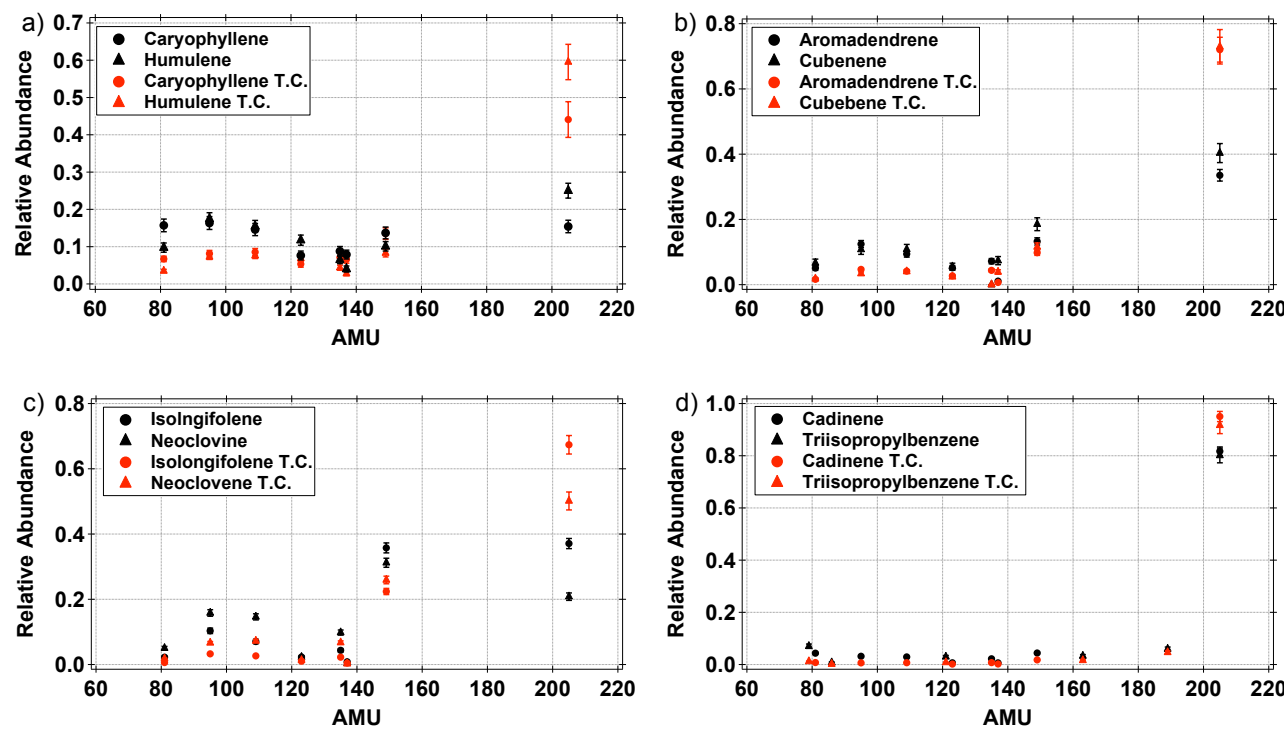

Fig. 3. Distributions of product ions and their abundances (at $117 \mathrm{Td}$ ) for seven SQT and TIPB as summarized in Table 2. Each panel contains two chemical species, showing similar fragmentation patterns probably due to their stereo-chemical similarity. The normalized abundance with (red) and without (black) the transmission correction (T.C. in the Label) are presented in different colors. Error bars indicate $1 \sigma$ of error. Note the different y-axis scales.
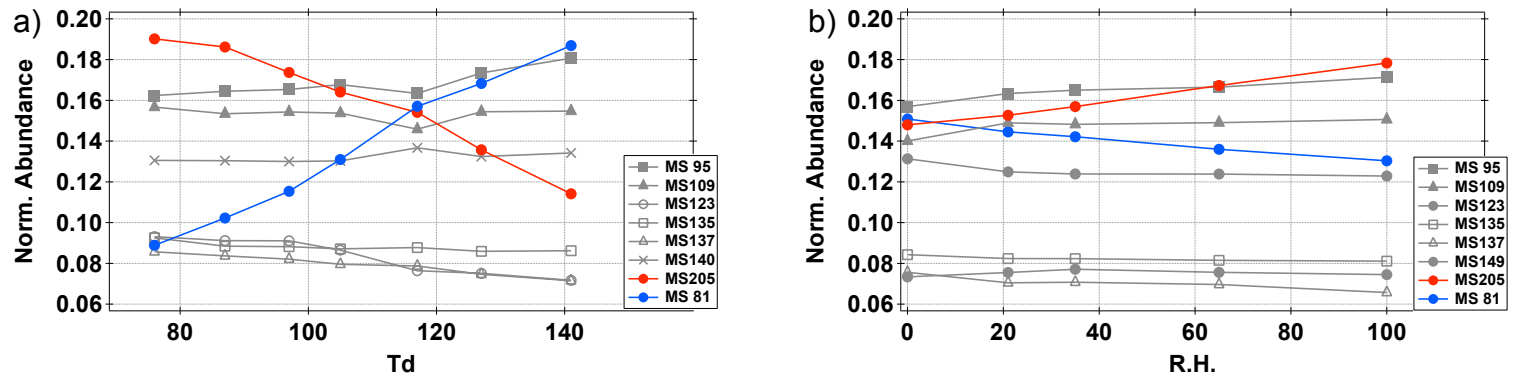

Fig. 4. Product ion distributions of $\beta$-caryophyllene as a function of (a) collisional energy in the drift tube and (b) relative humidity (\% at $\left.23^{\circ} \mathrm{C}\right)$.

(e.g. $<10 \%$ of $\mathrm{H}_{3} \mathrm{O}^{+}$), rapid charge transfer can occur (e.g. at the collisional limit) and contribute to additional peaks in PTR-MS spectra.

Overall, SQT investigated in this study exhibit the same fragment ions reported by Dhooghe et al. (2008) as summarized in Table 2. Individual fragmentation patterns grouped by SQT with similar molecular structures are shown in Fig. 3. Table 2 and Fig. 3 also present distributions of fragmented ion abundances corrected for the mass discrimination effect inferred from the regression equation shown in Fig. 1. Species with stable 6-member rings such as $\delta$-cadinene or the $\pi$-conjugated complex TIPB exhibit the least pronounced fragmentation. Compounds such as $\alpha$-humulene and $\beta$ caryophyllene, which consist of a larger size ring system, are prone to a higher degree of fragmentation. With the exception of $\alpha$-humulene and $\beta$-caryophyllene, the PTR-MS SQT spectra exhibit more pronounced fragmentation than those from SIFT-MS. Fragmentation can in principle occur for all SQT, where one major excited molecular parent ion is always $m / z 149^{+}$. It is worth noting that the major fragment ion observed in MT spectra $\left(\mathrm{m} / \mathrm{z}, 81^{+}\right)$suggests splitoff of the same neutral fragment $56 \mathrm{amu}\left(\mathrm{C}_{4} \mathrm{H}_{8}\right)$. In both cases this can be explained by Field's rule (McLafferty and Turecek, 1993), which suggests that an intermediate protonbound complex should dissociate preferentially to form a neutral with lower proton affinity (PA). This pattern can also be found for the major SQT product ions $\left(\mathrm{C}_{11} \mathrm{H}_{15} \mathrm{H}^{+}(\mathrm{m} / z\right.$ $\left.149^{+}\right)$) from $\mathrm{C}_{15} \mathrm{H}_{24} \mathrm{H}^{+}\left(\mathrm{m} / z 205^{+}\right)$. In summary, our results indicate that $\mathrm{m} / \mathrm{z} 205^{+}$is the most abundant ion for every SQT after consideration of the mass discrimination effect. The results are consistent with a similar previous study by Demarcke et al. (2009). 

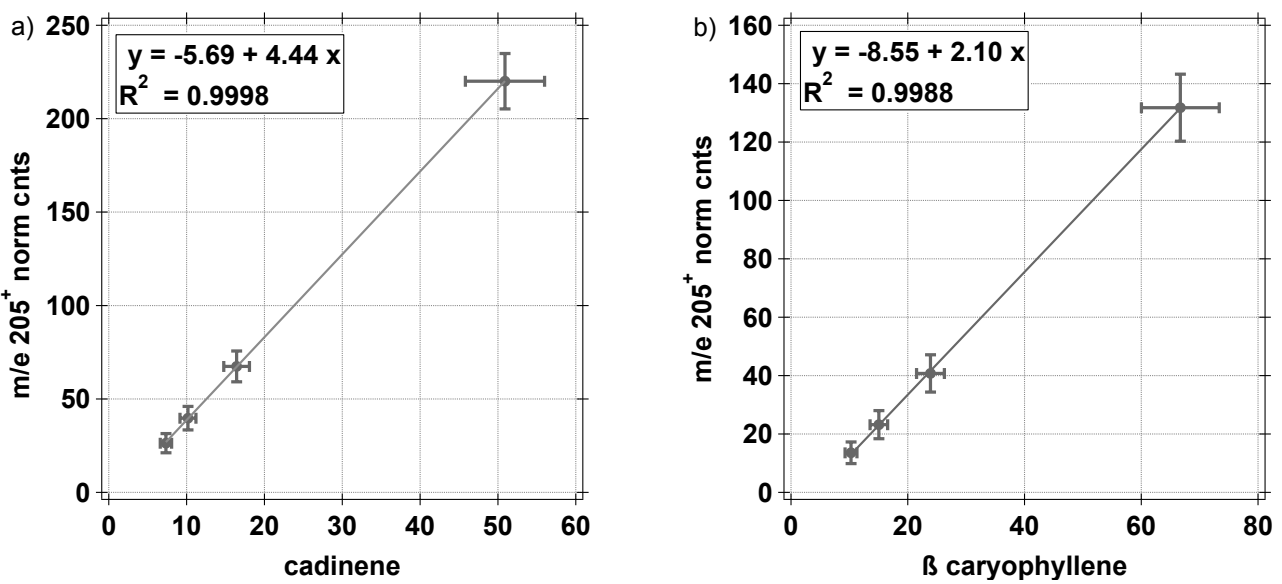

Fig. 5. Multi-point calibration results for (a) $\delta$-cadinene and (b) $\beta$-caryophyllene.

\subsection{2 $\mathrm{E} / \mathrm{N}$ and humidity dependence of observed prod- uct ion distributions}

Dependence of fragmentation patterns as a function of $\mathrm{E} / \mathrm{N}$ for $\beta$-caryophyllene, which exhibits the highest degree of dissociation, is presented in Fig. 4a. Higher collisional energies (higher $\mathrm{E} / \mathrm{N}$ ) result in a higher degree of fragmentation, especially toward $m / z 81^{+}$. This tendency was found for every SQT investigated in this study and the abundance of the product ions show clear anti-correlation with $\mathrm{m} / z 205^{+}$. The degree to which this happens is different for each species as summarized in Table 2, which contains normalized abundance changes for the highest and the lowest $\mathrm{E} / \mathrm{N}$ value chosen for this study. In the case of $\beta$-caryophyllene, the normalized abundance of $\mathrm{m} / \mathrm{z} 205^{+}$increases by a factor of two going from the highest to the lowest $\mathrm{E} / \mathrm{N}$ ( $141 \mathrm{Td}$ to $76 \mathrm{Td}$ ). Although a higher yield of $\mathrm{m} / \mathrm{z} 205^{+}$would result in better sensitivity at lower $\mathrm{E} / \mathrm{N}$, lower $\mathrm{E} / \mathrm{N}$ causes a higher degree of water clustering, which complicates analysis of other VOC due to a complex interplay between cluster formation $\left(\mathrm{RH}^{+}\left(\mathrm{H}_{2} \mathrm{O}\right)_{n}\right)$ and proton transfer reactions (de Gouw and Warneke, 2007; Hewitt et al., 2003). In general, E/ $\mathrm{N}$ of 120-130 Td is recommended as a good compromise between minimizing the interference of water clusters and maximizing the sensitivity for ambient VOC measurements (Hewitt et al., 2003). At E/N $117 \mathrm{Td}$ (our typical standard operational conditions and 2.3 torr and $600 \mathrm{~V}$ ), we found the first water cluster $\left(\mathrm{m} / 237^{+}\right)$to be less than $20 \%$ of $\mathrm{H}_{3} \mathrm{O}^{+}$at $100 \%$ relative humidity (at $23^{\circ} \mathrm{C}$ ). Figure $4 \mathrm{~b}$ presents the dependence of the fragmentation pattern of $\beta$-caryophyllene at various relative humidity. A lower degree of fragmentation $(\sim 20 \%)$ is observed as relative humidity is changed from $0 \%$ to $100 \%$. This tendency has also been reported for other compounds such as MT and related $\mathrm{C}_{10}$ VOC (Tani et al., 2004 and Tani et al., 2003). Tani et al. (2003) suggested that lower fragmentation in the presence of more water is due to a decrease in the average ion mobility, which is positively correlated with the kinetic energy of ions in the drift tube. Here we observe that the yield of the parent ion of $\beta$-caryophyllene can increase by $\sim 20 \%$ between $0 \%$ and $100 \%$ relative humidity. Consequently, less than $\sim 20 \%$ uncertainty in SQT quantification under ambient humidity conditions, which typically range between $30 \%$ to $100 \%$ in forest canopies, would be expected if this humidity effect is not corrected. This finding shows that SQT have similar humidity dependencies as MT ( 30\%; Tani et al., 2004).

\subsubsection{Analytical considerations for quantitative SQT measurements using PTR-MS}

In the previous section, we have characterized how much each mother $\left(\mathrm{m} / z 205^{+}\right)$and fragment ion contributes to the sum of the transmission-corrected total ion amount for each species. Based on the knowledge of fragmentation patterns listed in Table 2, we can calculate mixing ratios for each SQT using a theoretical sensitivity based on literature values of proton transfer reaction rate constants for MT and SQT. By comparing those theoretical mixing ratios with the values obtained from the CDS, we examined how accurately the sensitivity of SQT can be inferred. The calculated sensitivities for various other VOC were also compared with actual sensitivities based on the two gravimetrically prepared VOC standards. As an example, at 2.3 mbar drift tube pressure and $600 \mathrm{~V}(117 \mathrm{Td})$ drift tube voltage we calculate a theoretical sensitivity of $12 \mathrm{ncps} \mathrm{ppbv}^{-1}$ for a reaction rate constant of $2.5 \times 10^{-9}$ molecule $\mathrm{cm}^{3} \mathrm{~s}^{-1}$. Here we chose to base the theoretical sensitivity for SQT on an actual calibration factor inferred for camphene and multiplied this by 1.23 in order to account for the higher proton transfer reaction rate for SQT $\left(3.0 \times 10^{-9}\right.$ molecule $\mathrm{cm}^{3} \mathrm{~s}^{-1}$; Dhooghe et al., 2008) compared to MT $\left(2.5 \times 10^{-9}\right.$ molecule $\mathrm{cm}^{3} \mathrm{~s}^{-1}$; Zhao and Zhang, 2004). The measured sensitivity for camphene agreed to within $20 \%$ of the theoretically calculated sensitivity. In order to arrive at a final SQT concentration, 


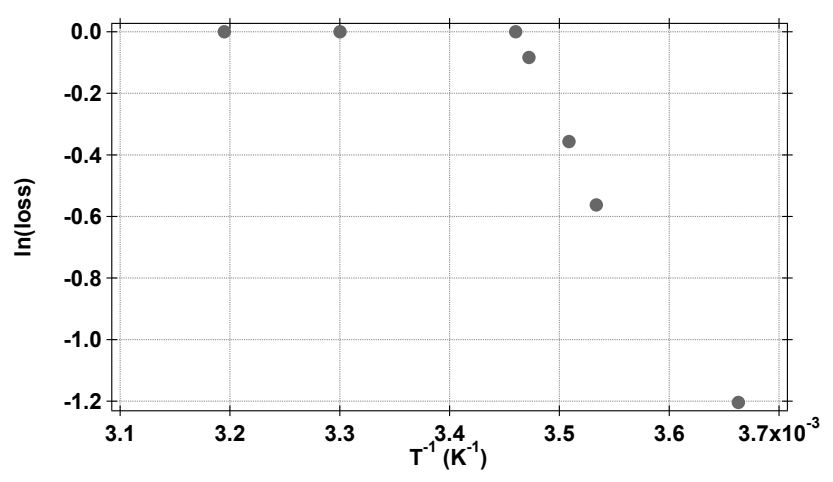

Fig. 6. Loss (output mixing ratio/input mixing ratio) of $\beta$ caryophyllene through $40 \mathrm{~m}$ of Teflon line as a function of temperature.

measured in the output of each channel of the CDS, we first corrected each fragment according to the transmission curve, and then summed product ions as shown in Table 2 before applying the theoretical sensitivity of SQT. Quantification results were compared with data independently inferred from the GC-FID. The concentration ratios between PTR-MS and GC-FID at two different E/N settings for each species are summarized in Table 3. The table lists the ratios of the PTRMS/GC-FID results for two cases. Only the two major ions $(\mathrm{m} / \mathrm{z}, 149+$ and $\mathrm{m} / \mathrm{z}, 205+)$ and every fragment ion were used to calculate corresponding mixing ratios. A comparison with the GC-FID results shows that for most SQT investigated here mixing ratios inferred from PTR-MS agree to within $10 \%$ when every product ion is accounted for. They agree to within a systematic error of $\sim 50 \%(\sim 20 \%$ averaged over all investigated SQT species) if the two major ions (MS149+ and MS $205^{+}$) are considered and to within $30 \%$ on average if only the parent ion $\left(\mathrm{m} / z, 205^{+}\right)$is taken into account. It is noted that this quantification scheme needs to be applied carefully for ambient measurements because of the potential presence of other BVOC that can produce ions at $m / z 149^{+}$ (e.g. methyl chavicol).

Figure 5 presents multi-point calibrations for $\beta$ caryophyllene and $\delta$-cadinene, which represent the most and the least fragmented SQT observed during this study. High linearity is observed for both species, as illustrated by the high $R^{2}$ values. For the parent ion $\mathrm{m} / \mathrm{z} 205^{+}, \delta$-cadinene exhibits a higher sensitivity $\left(57.72 \mathrm{cpsppbv}^{-1}\right.$ at $1.3 \times 10^{7} \mathrm{~Hz}$ of $\mathrm{H}_{3} \mathrm{O}^{+}$) than that of $\beta$-caryophyllene ( $31.85 \mathrm{cps} \mathrm{ppbv}^{-1}$ at $1.3 \times 10^{7} \mathrm{cps}$ of $\mathrm{H}_{3} \mathrm{O}^{+}$) due to the less pronounced fragmentation of $\delta$-cadinene. For a one-minute integration time on $\mathrm{m} / \mathrm{z} 205^{+}$the estimated limits of detection (LOD) (based on the sensitivity inferred from Fig. 5 and background measurements) are $50 \mathrm{pptv}$ and $91 \mathrm{pptv}$ for $\delta$-cadinene and $\beta$-caryophyllene, respectively. This calculation is based on Poisson Statistics using a signal to noise ratio $(\mathrm{S} / \mathrm{N})$ of 2 according to $\mathrm{LOD}=2 \times \sigma_{\text {blank }} /$ sensitivity, where
Table 3. Ratios of the quantitative results based on GC-FID analysis to PTR-MS-calculated mixing ratios deduced from transmissioncorrected raw counts and reaction rate constants. See text for the detailed calculation scheme. These ratios are summarized for two different $\mathrm{E} / \mathrm{N}$ conditions taking all product ions and two major product ions $\left(\mathrm{m} / \mathrm{z} 205^{+}\right.$and $\left.\mathrm{m} / \mathrm{z} 149^{+}\right)$into account.

\begin{tabular}{lrrrr}
\hline Species & \multicolumn{2}{c}{ All Fragments } & \multicolumn{2}{c}{$\mathrm{m} / \mathrm{z} 205^{+}$and $\mathrm{m} / \mathrm{z} 149^{+}$} \\
\hline & EN105 & EN117 & EN105 & EN117 \\
\hline$\beta$-caryophyllene & 1.10 & 1.04 & 0.63 & 0.58 \\
$\alpha$-humulene & 0.91 & 0.79 & 0.63 & 0.55 \\
aromadendrene & 1.10 & 0.86 & 0.92 & 0.71 \\
$\alpha$-cubebene & 1.28 & 1.19 & 1.11 & 0.74 \\
neoclovene & 1.07 & 0.91 & 0.93 & 0.79 \\
isolongifolene & 0.66 & 0.75 & 0.66 & 0.75 \\
$\delta$-cadinene & 1.19 & 1.04 & 1.13 & 1.04 \\
Average & 1.04 & 0.94 & 0.86 & 0.74 \\
STD & 0.203 & 0.157 & 0.218 & 0.161 \\
\hline
\end{tabular}

$\sigma_{\text {blank }}$ is the standard deviation of background count rates. This estimation suggests that PTR-MS can be a possible analytical method for measuring SQT in forest canopies if long integration times are chosen. For example a $10 \mathrm{~min}$ integration time would allow the measurement of SQT concentrations down to $\sim 20 \mathrm{pptv}$.

\subsection{SQT field measurements at the PROPHET tower}

\subsubsection{Investigation of line losses of B-caryophellene}

Figure 6 shows the relative fraction of B-caryophyllene (20 ppbv) lost between inlet and outlet of a $40 \mathrm{~m}$ long Teflon line (O.D.1/4"). The figure depicts the logarithm of the ratio between outlet to inlet concentration as a function of temperature. Below $16^{\circ} \mathrm{C}, \beta$-caryophyllene started to decrease. The relative loss at $12^{\circ} \mathrm{C}$ for example was $30 \%$. When the temperature was increased after each low temperature experiment, a spike of $\beta$-caryophyllene concentration was observed in the outlet, suggesting desorption of previously retained B-caryophyllene off the walls. Our observations suggest that line losses become significant below $16^{\circ} \mathrm{C}$ under the conditions of this experiment. These results suggest that heating of sampling lines is recommended for SQT measurements in ambient air when temperatures below $20^{\circ} \mathrm{C}$ are expected. Other previous experiments with the CDS have shown that SQT adsorption losses are also a function of the SQT absolute levels, with relative loss rates becoming smaller with decreasing concentrations. As the tubing tests were performed at concentration levels that were $\sim 100$ times 
larger than expected ambient air SQT levels, the finding from this experiment should be considered as an upper limit.

\subsubsection{PROPHET tower measurements}

The PTR-MS instrument was deployed at a deciduous North American forest (Michigan, USA) for a 3-week period in August 2005 (23 July 2005- 12 August 2005). Ambient VOC concentration gradients measured throughout the canopy were used to investigate of distribution of important terpenoid compounds. Here, we present data for isoprene, total MT and total SQT. Isoprene and total MT were calibrated with a standard mixture during the field campaign as described in Sect. 2.1 and total SQT are deduced with the calibration factors in Sect. 3.1. We applied the transmission efficiency of the PTR-MS system and the calculated proton transfer reaction constant to deduce total SQT mixing ratios from the raw counts of $\mathrm{m} / \mathrm{z} 205^{+}$. Whole air canister samples (SUMMA Canisters, Air Toxics LTD, Portland Oregon) were also collected on several occasions (26 July 2005, 2 August 2005 and 5 August 2005) and the analysis data are used to characterize the ambient distribution of individual MT at this site. The most prevalent MT were found in the following order: $\alpha$-pinene (33\%), $\beta$-pinene (28\%), $\Delta$-limonene $(20 \%)$, terpinolene (9\%), $\alpha$-terpinene (5\%) and camphene (5\%). Although this MT speciation in ambient measurements is different from branch enclosure measurement results, which indicated that ocimene is the most abundant MT (Ortega et al., 2007), the ambient air speciation results were adopted for the canopy scale approach.

Ambient SQT concentrations were inferred from PTR-MS measurements based on $\mathrm{m} / \mathrm{z} 205^{+}$under the assumption that SQT is the major contributing species to the $\mathrm{m} / \mathrm{z} 205^{+}$ion counts. We report a best estimate and upper and lower limits due to potential fragmentation based on species investigated in Sect. 3.1. Emissions of isoprene, MT and SQT were estimated using vertical gradient data and the model described in Sect. 2.5. The right panel of Fig. 7 depicts average noontime (10:00-14:00 local time) concentration profiles of isoprene, MT, and SQT from the PTR-MS measurements. The left panel shows the differential vegetation area index (VAI). It is noted that concentration profiles started at $8 \mathrm{~m}$ above ground due to constraints imposed by the laboratory building at the base of the measurement tower. Finally, the middle panel depicts isoprene, total MT and total SQT emission rates throughout the canopy inferred from measured concentration gradients using the Inverse Lagrangian Transport (ILT) model as described in Sect. 2.5. Lower limits of atmospheric SQT lifetimes, estimated to be about $160 \mathrm{~s}$ due to reaction with ozone, are based on that for $\beta$-caryophyllene $\left(\mathrm{k}_{O 3+\beta \text {-caryophyllene }}=1.2 \times 10^{-14}\right.$ molecule $\mathrm{e}^{-1} \mathrm{~cm}^{3} \mathrm{~s}^{-1}$ at an ozone concentration of $5 \times 10^{11}$ molecule $\mathrm{cm}^{-3}$; Shu and Atkinson, 1995). Chemical loss of $\beta$-caryophyllene in forest canopies is expected to be primarily controlled by ozone rather than $\mathrm{OH}$ (Shu and Atkinson, 1995; and Ciccioli et al., 1999). We included this reactive loss when calculating sesquiterpene emission rates with the ILT model, but found that it would at most increase the overall emission by $13 \%$.

It can be seen that BVOC concentration profiles are not very indicative of source and sink distributions inside the canopy. The estimated emission profiles, shown in Fig. 7, on the other hand show clear correlation with the biomass density peaking in the upper part of the canopy. The estimated emission rates shown in Fig. 7 are based on a volume average where each level spans $5 \mathrm{~m}$. Vertical integration of individual emission rates yields total ecosystem scale fluxes of $4.5 \pm 1.0,0.21 \pm 0.06$ and $0.10 \pm 0.05 \mathrm{mg} \mathrm{m}^{-2} \mathrm{~h}^{-1}$ for isoprene, MT and SQT respectively. For comparison, noontime average canopy scale concentrations during the whole study were $14.6 \pm 0.91$ (isoprene), $1.21 \pm 0.061$ (MT) and $0.00160 \pm 0.00064$ (SQT) $\mu \mathrm{g} \mathrm{m}^{-3}$ with error margins indicating concentration variations of the mean profiles shown in Fig. 7. Isoprene emissions are comparable ( 20\%) to above canopy fluxes inferred from PTR-MS-eddy covariance measurements (Turnipseed et al., 2009). MT eddy covariance measurements were conducted on two consecutive days (31 July 2005-1 August 2005) during the middle of the study. Based on these flux measurements the average ratio between MT (0.39 $\mathrm{mg} \mathrm{m}^{2} \mathrm{hr}^{-1}$, day time median flux) and isoprene (7.95 $\mathrm{mg} \mathrm{m}^{2} \mathrm{~h}^{-1}$, day time median flux) fluxes was $5.1 \%$, which compares favorably to the study average flux ratio of $4.7 \%$ inferred from the ILT dispersion model (Fig. 7). Ortega et al. (2007) reported a MT to isoprene emission ratio of $4 \%$ based on branch enclosure measurements, also in good agreement with our estimate. On the other hand, their branch enclosure measurements suggested a SQT/isoprene ratio of only $0.3 \%$. Based on the ambient air observations presented in this paper we observe a SQT/isoprene flux ratio on the order of $2-3 \%$, roughly a factor of 10 higher. Differing results for SQT/isoprene ratios between branch enclosure data and the PTR-MS flux results suggest the necessity for further research to determine whether (1) other sources of SQT in the ecosystem play a more significant role than thought (e.g. emissions from soil or bark), (2) a significant difference between leaves growing in the understory (shade) and those growing in the upper part of the canopy (sun) exists (because most of branch enclosure measurements have been restricted to accessible areas in the lower part of the canopies) or (3) the if the presence of other unidentified VOC (including SQT that are not identified by GC-MS) is contributing to the $\mathrm{m} / \mathrm{z}$ $205^{+}$mass channel recorded by PTR-MS in ambient air. A comprehensive measurement intercomparison between different techniques such as GC-MS and PTR-Time of Flight techniques in ambient air will be needed to answer these questions.

Since large missing sources of reactive terpenes have been suggested previously in this ecosystem based on $\mathrm{OH}$ reactivity measurements (Di Carlo et al., 2004), we examined whether the SQT and MT levels measured in ambient air could resolve the reported missing $\mathrm{OH}$ reactivity. To an- 


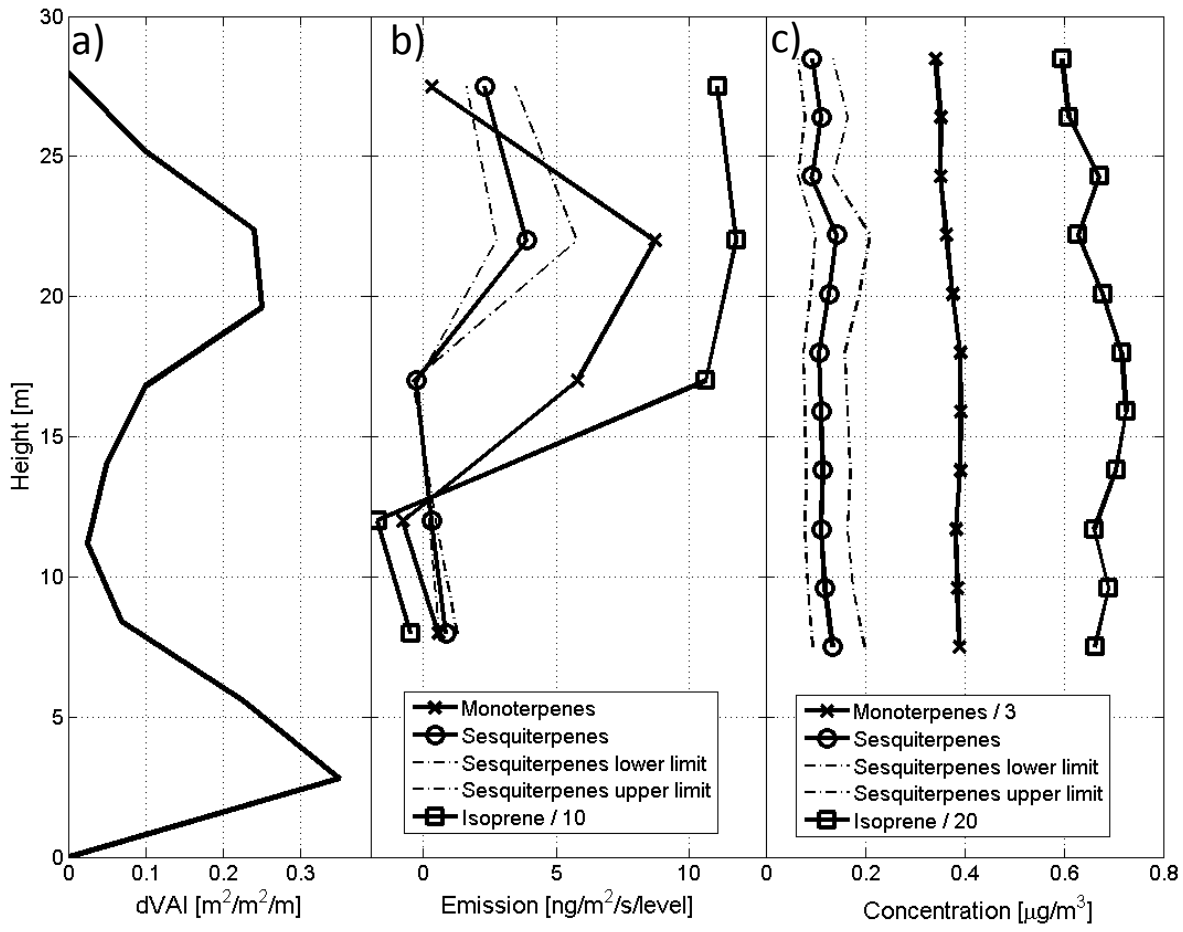

Fig. 7. Vertical distributions of measured (a) VAI (Vegetation Area Index), (b) emission (c) concentration from PROPHET tower, during 23 July 2005-12 August 2005. The vertical distributions of emission (b) is calculated by the Lagrangian dispersion model (see text for detail) using vertical distributions of (a) and (c).

Table 4. Summary for mixing ratios of isoprene, MT, and SQT, measured by PTR-MS. The MT speciation is deduced from GC-MS data. $\mathrm{OH}$ reactivity estimations along with reaction constants are summarized for each species.

\begin{tabular}{llll}
\hline Species & Mixing Ratio (ppbv) & $\mathrm{kOH}\left(\mathrm{cm}^{3}\right.$ molecul $\left.^{-1} \mathrm{~s}^{-1}\right)$ & OH Reactivity $\left(\mathrm{s}^{-1}\right)$ \\
\hline isoprene & 4.8 & ${ }^{\mathrm{a}} 1.00 \times 10^{-10}$ & 11.8 \\
$\mathrm{MT}$ & 0.2 & & 0.58 \\
$\alpha$-Pinene & 0.06 & ${ }^{\mathrm{a}} 5.45 \times 10^{-11}$ & 0.087 \\
Camphene & 0.01 & $\mathrm{a}_{5} .33 \times 10^{-11}$ & 0.014 \\
$\beta$-Pinene & 0.05 & $\mathrm{a}_{7} .98 \times 10^{-11}$ & 0.11 \\
Terpinolene & 0.02 & $\mathrm{a}_{2} .20 \times 10^{-10}$ & 0.10 \\
$\delta$-Limonene & 0.04 & $\mathrm{a}_{1} 1.71 \times 10-10$ & 0.17 \\
$\alpha$-Terpinene & 0.01 & $\mathrm{a}_{3} .63 \times 10-10$ & 0.096 \\
SQT & 0.02 & $\mathrm{~b}_{2.00 \times 10-10}$ & 0.1 \\
\hline
\end{tabular}

${ }^{a}$ from Atkinson (1997) ${ }^{b}$ from Shu and Atkinson (1995)

swer this question we calculated an $\mathrm{OH}$ reactivity based on ambient measurements of MT as explained at the beginning of this section. The summed MT reactivity was inferred from the measured MT distribution obtained from the GC-MS analyses and scaled to the study average MT concentration based on PTR-MS. An upper limit of the reactivity of SQT was calculated by taking $\beta$-caryophyllene $\left(\mathrm{k}_{\mathrm{OH}}=2 \times 10^{-10}\right.$ molecule ${ }^{-1} \mathrm{~cm}^{3} \mathrm{~s}^{-1}$ ) as the most reactive species (Shu and Atkinson, 1995). The variables used for the calculations are summarized in Table 4 . Based on these 
assumptions the calculated $\mathrm{OH}$ reactivity was dominated by isoprene $\left(11.8 \mathrm{~s}^{-1}\right)$, followed by MT $\left(0.6 \mathrm{~s}^{-1}\right)$ and SQT $\left(0.1 \mathrm{~s}^{-1}\right)$. For comparison, the missing $\mathrm{OH}$ reactivity based on $\mathrm{OH}$ reactivity measurements (Di Carlo et al., 2004) was reported between $1-4 \mathrm{~s}^{-1}$. At $23^{\circ} \mathrm{C}$ (average daytime temperature during this study) our observations of MT and SQT could explain $30 \%$ of the missing fraction hypothesized by Di Carlo et al. (2004), who did not have MT and SQT measurements available during their study. There have been reports that GC-MS techniques might miss reactive MT (Lee et al., 2005). PTR-MS however allows for a constraining of the total MT concentration, which was $0.2 \mathrm{ppbv}$ during this study. In order to explain the missing $\mathrm{OH}$ reactivity $\mathrm{Di}$ Carlo et al. (2004) inferred a reactive terpene concentration, equivalent to $0.5 \mathrm{ppbv}$. Very accurate concentrations of isoprene and its oxidation products would be required for a further evaluation of our findings and the conclusions drawn by Di Carlo et al. (2004) since the measurement uncertainty of isoprene, the dominant BVOC in this ecosystem, can contribute a significant uncertainty in the $\mathrm{OH}$ reactivity assessments (Edwards et al., 2007).

\section{Conclusions and summary}

We conducted comprehensive experiments to explore the feasibility of measuring atmospheric SQT concentrations and fluxes using PTR-MS. Systematic investigation of seven SQT species showed that these species produced the same product ions during proton transfer reactions with $\mathrm{H}_{3} \mathrm{O}^{+}$as summarized in Table 2. Although the relative abundance of product ions depends on various factors such as collisional energy of the drift tube, humidity and stereochemistry, the observed ions were consistent with those reported in a recent SIFT-MS study (Dhooghe et al., 2008). The most abundant product ions $\left(\mathrm{m} / \mathrm{z} 205^{+}\right.$and $\left.\mathrm{m} / \mathrm{z} 149^{+}\right)$account for more than $60 \%$ of the transmission-corrected total ion abundance under typical operating conditions for PTR-MS (117 Td); this results in a $\sim 20 \%$ uncertainty when using a generic SQT calibration factor. When only $\mathrm{m} / \mathrm{z} 205^{+}$is considered, the uncertainty increases to $30 \%$. The estimated mixing ratios, calculated from the proton transfer reaction constants and total transmission-corrected counts of all product ions showed good agreement $(\sim 10 \%)$ with the reference values from the SQT standard generation system. This indicates the possibility that total SQT concentrations can be measured by PTRMS if mass discrimination is carefully characterized. The estimated detection limit (less than 20 pptv for ten-minute integration time) suggests that PTR-MS can be a viable tool for ambient measurements of SQT when sufficiently long integration times are chosen.

Ecosystem scale observations of isoprene, MT, and SQT suggest significant fluxes of SQT. MT and SQT could account for $30 \%$ of the missing $\mathrm{OH}$ reactivity hypothesized at this site. These findings highlight the importance of ecosys- tem scale observations of BVOC. Whether these observations can be generalized to other ecosystems will require a combination of bottom-up (e.g. branch level emissions) and top-down (e.g. ecosystem scale flux) measurements. PTRMS can be a useful tool for constraining the magnitude of ecosystem scale SQT concentrations and emissions. Further technique development based on TOF-MS and ion trap (IT)MS technology will be needed to improve the accuracy of SQT measurements by PTR-MS. Especially, the TOF-MS ability to eliminate isobaric interferences can differentiate possible interferences on $\mathrm{m} / \mathrm{z} 205^{+}$(e.g. oxygenated compounds and SQT) and $m / z 149^{+}$(e.g. methyl chavicol and SQT fragment). This will also allow a more accurate evaluation of possible interferences on $\mathrm{m} / \mathrm{z} 205^{+}$and, when combined with field intercomparisons based on GC-MS, help reduce uncertainties of SQT emission and ambient measurements.

Acknowledgements. We are grateful to M. A. Carroll for use of the Prophet tower facility. This work was supported in part by National Science Foundation grant ATM-0608582. The National Center for Atmospheric Research is operated by the University Corporation for Atmospheric Research under sponsorship from the National Science Foundation. Any opinions, findings and conclusions or recommendations expressed in this publication are those of the authors and do not necessarily reflect the views of the National Science Foundation.

Edited by: H. Schlager

\section{References}

Atkinson, R.: Gas-phase tropospheric chemistry of volatile organic compounds: 1. Alkanes and Alkenes, J. Phys. Chem. Ref. Data, 26, 215-290, 1997.

Baldwin, I. T., Halitschke, R., Paschold, A., von Dahl, C. C., and Preston, C. A.: Volatile signaling in plant-plant interactions: "Talking trees" in the genomics era, Science, 311, 812-815, 2006.

Bonn, B., Hirsikko, A., Hakola, H., Kurtén, T., Laakso, L., Boy, M., Dal Maso, M., Mäkelä, J. M., and Kulmala, M.: Ambient sesquiterpene concentration and its link to air ion measurements, Atmos. Chem. Phys., 7, 2893-2916, 2007, http://www.atmos-chem-phys.net/7/2893/2007/.

Boy, M., Karl, T., Turnipseed, A., Mauldin, R. L., Kosciuch, E., Greenberg, J., Rathbone, J., Smith, J., Held, A., Barsanti, K., Wehner, B., Bauer, S., Wiedensohler, A., Bonn, B., Kulmala, M., and Guenther, A.: New particle formation in the Front Range of the Colorado Rocky Mountains, Atmos. Chem. Phys., 8, 15771590, 2008, http://www.atmos-chem-phys.net/8/1577/2008/.

Curtis, P. S., Hanson, P. J., Bolstad, P., Barford, C., Randolph, J. C., Schmid, H. P., and Wilson, K. B.: Biometric and eddycovariance based estimates of annual carbon storage in five eastern North American deciduous forests, Agr. Forest Meteorol., 113, 3-19, 2002.

Dawson, P. H.: Fringing fields in quadrupole-type mass analyzers, J. Vac. Sci. Technol., 9, 487-491, 1972. 
Dawson, P. H.: Higher zones of stability for quadrupole mass filter, J. Vac. Sci. Technol., 11, 1151-1153, 1974.

Dawson, P. H.: Acceptance of quadrupole mass filter, Int. J. Mass Spectrom., 17, 423-445, 1975.

de Gouw, J. and Warneke, C.: Measurements of volatile organic compounds in the earths atmosphere using proton-transferreaction mass spectrometry, Mass Spectrom. Rev., 26, 223-257, 2007.

Demarcke, M., Amelynck, C., Schoon, N., Dhooghe, F., Van Langenhove, H., and Dewulf, J.: Laboratory studies in support of the detection of sesquiterpenes by proton-transfer-reaction-massspectrometry, Int. J. Mass Spectrom., 279, 156-162, 2009

Dhooghe, F., Amelynck, C., Schoon, N., Debie, E., Bultinck, P., and Vanhaecke, F.: A selected ion flow tube study of the reactions of $\mathrm{H}_{3} \mathrm{O}^{+}, \mathrm{NO}^{+}$and $\mathrm{O}_{2}^{-}$with a series of sesquiterpenes, Int. J. Mass Spectrom., 272, 137-148, 2008.

Di Carlo, P., Brune, W. H., Martinez, M., Harder, H., Lesher, R., Ren, X. R., Thornberry, T., Carroll, M. A., Young, V., Shepson, P. B., Riemer, D., Apel, E., and Campbell, C.: Missing OH reactivity in a forest: Evidence for unknown reactive biogenic VOCs, Science, 304, 722-725, 2004.

Duhl, T. R., Helmig, D., and Guenther, A.: Sesquiterpene emissions from vegetation: a review, Biogeosciences, 5, 761-777, 2008, http://www.biogeosciences.net/5/761/2008/.

Edwards, G. D., Shepson, P. B., Grossenbacher, J. W., Wells, J. M., Patterson, G. E., Barket, D. J., Pressley, S., Karl, T., and Apel, E.: Development of an automated cylindrical ion trap mass spectrometer for the determination of atmospheric volatile organic compounds, Anal. Chem., 79, 5040-5050, 2007.

Farmer, E. E.: Surface-to-air signals, Nature, 411, 854-856, 2001.

Gershenzon, J.: Plant volatiles carry both public and private messages, P. Natl. A. Sci. USA, 104, 5257-5258, 2007.

Griffin, R. J., Cocker, D. R., Seinfeld, J. H., and Dabdub, D.: Estimate of global atmospheric organic aerosol from oxidation of biogenic hydrocarbons, Geophys. Res. Lett., 26, 2421-2724, 1999.

Hansel, A., Jordan, A., Warneke, C., Holzinger, R., Wisthaler, A., and Lindinger, W.: Proton-transfer-reaction mass spectrometry (PTR-MS): on-line monitoring of volatile organic compounds at volume mixing ratios of a few pptv, Plasma Sources Sci. T., 8, 332-336, 1999.

Helmig, D. and Arey, J.: Organic chemicals in the air at Whitacker Forest - Sierra Nevada Mountains, California, Sci. Total Environ., 112, 233-250, 1992.

Helmig, D., Bocquet, F., Pollmann, J., and Revermann, T.: Analytical techniques for sesquiterpene emission rate studies in vegetation enclosure experiments, Atmos. Environ., 38, 557-572, doi:10.1016/j.atmosenv.2003.10.012, 2004.

Helmig, D., Ortega, J., Duhl, T., Tanner, D., Guenther, A., Harley, P., Wiedinmyer, C., Milford, J., and Sakulyanontvittaya, T.: Sesquiterpene emissions from pine trees - Identifications, emission rates and flux estimates for the contiguous United States, Environ. Sci. Technol., 41, 1545-1553, doi:10.1021/es0618907, 2007.

Helmig, D., Revermann, T., Pollmann, J., Kaltschmidt, O., Hernandez, A. J., Bocquet, F., and David, D.: Calibration system and analytical considerations for quantitative sesquiterpene measurements in air, J. Chromatogr. A, 1002, 193-211, 2003.

Hewitt, C. N., Hayward, S., and Tani, A.: The application of proton transfer reaction-mass spectrometry (PTR-MS) to the monitoring and analysis of volatile organic compounds in the atmosphere, J. Environ. Monitor., 5, 1-7, 2003.

Hoffmann T.: Adsorptive preconcentration technique including oxidant scavenging for the measurement of reactive natural hydrocarbons in ambient air. Fres. J. Anal. Chem., 351, 41-47, 1995.

Hoffmann, T., Odum, J. R., Bowman, F., Collins, D., Klockow, D., Flagan, R. C., and Seinfeld, J. H.: Formation of organic aerosols from the oxidation of biogenic hydrocarbons, J. Atmos. Chem., 26, 189-222, 1997.

Holzinger, R., Lee, A., Paw, K. T., and Goldstein, U. A. H.: Observations of oxidation products above a forest imply biogenic emissions of very reactive compounds, Atmos. Chem. Phys., 5, $67-75,2005$, http://www.atmos-chem-phys.net/5/67/2005/.

Jaoui, M., Leungsakul, S., and Kamens, R. M.: Gas and particle products distribution from the reaction of beta-caryophyllene with ozone, J. Atmos. Chem., 45, 261-287, 2003.

Karl, T., Guenther, A., Lindinger, C., Jordan, A., Fall, R., and Lindinger, W.: Eddy covariance measurements of oxygenated volatile organic compound fluxes from crop harvesting using a redesigned proton-transfer-reaction mass spectrometer, J. Geophys. Res.-Atmos., 106, 24157-24167, 2001.

Karl, T., Guenther, A., Yokelson, R. J., Greenberg, J., Potosnak, M., Blake, D. R., and Artaxo, P.: The tropical forest and fire emissions experiment: Emission, chemistry, and transport of biogenic volatile organic compounds in the lower atmosphere over Amazonia, J. Geophys. Res.-Atmos., 112, D18302 doi:10.1029/2007JD008539, 2007.

Karl, T., Harley, P., Guenther, A., Rasmussen, R., Baker, B., Jardine, K., and Nemitz, E.: The bi-directional exchange of oxygenated VOCs between a loblolly pine (Pinus taeda) plantation and the atmosphere, Atmos. Chem. Phys., 5, 3015-3031, 2005, http://www.atmos-chem-phys.net/5/3015/2005/.

Karl, T., Potosnak, M., Guenther, A., Clark, D., Walker, J., Herrick, J. D., and Geron, C.: Exchange processes of volatile organic compounds above a tropical rain forest: Implications for modeling tropospheric chemistry above dense vegetation, J. Geophys. Res.-Atmos., 109, D18306, doi:10.1029/2004JD004738, 2004.

Kesselmeier, J., and Staudt, M.: Biogenic volatile organic compounds (VOC): An overview on emission, physiology and ecology, J. Atmos. Chem., 33, 23-88, 1999.

Kurpius, M. R. and Goldstein, A. H.: Gas-phase chemistry dominates $\mathrm{O}_{3}$ loss to a forest, implying a source of aerosols and hydroxyl radicals to the atmosphere, Geophys. Res. Lett., 30, doi:10.1029/2002GL016785, 2003

Lee, A., Goldstein, A. H., Keywood, M. D., Gao, S., Varutbangkul, V., Bahreini, R., Ng, N. L., Flagan, R. C., and Seinfeld, J. H.: Gas-phase products and secondary aerosol yields from the ozonolysis of ten different terpenes, J. Geophys. Res.-Atmos., 111, D07302, doi:10.1029/2005JD006437, 2006.

Lee, A., Schade, G. W., Holzinger, R., and Goldstein, A. H.: A comparison of new measurements of total monoterpene flux with improved measurements of speciated monoterpene flux, Atmos. Chem. Phys., 5, 505-513, 2005, http://www.atmos-chem-phys.net/5/505/2005/

Liao, H., Henze, D. K., Seinfeld, J. H., Wu, S. L., and Mickley, L. J.: Biogenic secondary organic aerosol over the United States: Comparison of climatological simulations 
with observations, J. Geophy. Res.-Atmos., 112, 19, D06201, doi:10.1029/2006jd007813, 2007.

Lindinger, W., Hansel, A., and Jordan, A.: Proton-transfer-reaction mass spectrometry (PTR-MS): on-line monitoring of volatile organic compounds at pptv levels, Chem. Soc. Rev., 27, 347-354, 1998.

McLafferty, F. W. and Turecek, F.: Interpretation of mass spectra, University Science Books, Sausalito, CA, 54-55, 1993.

Ortega, J., Helmig, D., Guenther, A., Harley, P., Pressley, S., and Vogel, C.: Flux estimates and $\mathrm{OH}$ reaction potential of reactive biogenic volatile organic compounds (BVOCs) from a mixed northern hardwood forest, Atmos. Environ., 41, 54795495, 2007.

Pollmann, J., Ortega, J., and Helmig, D.: Analysis of atmospheric sesquiterpenes: Sampling losses and mitigation of ozone interferences, Environ. Sci. Technol., 39, 9620-9629, 2005.

Raupach, M. R.: Applying lagrangian fluid-mechanics to infer scalar source distributions from concentration profiles in plant canopies, Agr. Forest Meteorol., 47, 85-108, 1989.

Schnee, C., Kollner, T. G., Held, M., Turlings, T. C. J., Gershenzon, J., and Degenhardt, J.: The products of a single maize sesquiterpene synthase form a volatile defense signal that attracts natural enemies of maize herbivores, P. Natl. A. Sci. USA, 103, 11291134, 2006.

Shu, Y. H., and Atkinson, R.: Atmospheric lifetimes and fates of a series of sesquiterpenes, J. Geophy. Res.-Atmos., 100, 7275$7281,1995$.

Spanel, P. and Smith, D.: Reactions of hydrated hydronium ions and hydrated hydroxide ions, with some hydrocarbons and oxygenbearing organic-molecules, J. Phys. Chem., 99, 15551-15556, 1995.
Steinbacher, M., Dommen, J., Ammann, C., Spirig, C., Neftel, A., and Prévôt, A. S. H.: Performance characteristics of a protontransfer-reaction mass spectrometer (PTR-MS) derived from laboratory and field measurements, Int. J. Mass Spectrom., 239, 117-128, 2004.

Taipale, R., Ruuskanen, T. M., Rinne, J., Kajos, M. K., Hakola, H., Pohja, T., and Kulmala, M.: Technical Note: Quantitative long-term measurements of VOC concentrations by PTR-MS measurement, calibration, and volume mixing ratio calculation methods, Atmos. Chem. Phys., 8, 6681-6698, 2008, http://www.atmos-chem-phys.net/8/6681/2008/.

Tani, A., Hayward, S., Hansel, A., and Hewitt, C. N.: Effect of water vapour pressure on monoterpene measurements using proton transfer reaction-mass spectrometry (PTR-MS), Int. J. Mass Spectrom., 239, 161-169, 2004.

Tani, A., Hayward, S., and Hewitta, C. N.: Measurement of monoterpenes and related compounds by proton transfer reaction-mass spectrometry (PTR-MS), Int. J. Mass Spectrom. 223, 561-578, 2003.

Turnipseed, A. A., Pressley, S. N., Karl, T., Lamb, B., Nemitz, E., Allwine, E., Cooper, W. A., Shertz, S., and Guenther, A. B.: The use of disjunct eddy sampling methods for the determination of ecosystem level fluxes of trace gases, Atmos. Chem. Phys., 9, 981-994, 2009, http://www.atmos-chem-phys.net/9/981/2009/.

Zhao, J. and Zhang, R. Y.: Proton transfer reaction rate constants between hydronium ion $\left(\mathrm{H}_{3} \mathrm{O}^{+}\right)$and volatile organic compounds, Atmos. Environ., 38, 2177-2185, 2004. 